\title{
Cue-induced memory interference in the rat
}

\author{
WILLIAM C. GORDON, ROBERT R. MOWRER, CHARLES P. McGINNIS, \\ and MARTHA J. McDERMOTT \\ University of New Mexico, Albuquerque, New Mexico
}

\begin{abstract}
Rats were trained on passive avoidance and then active avoidance, and then were tested for retention of the active response. Prior passive training interfered with retention of the active response if all training and testing occurred in one context. Significantly less interference resulted when the passive avoidance context differed from that used for active training and testing. However, significant interference did result when animals given passive training in a different context were reminded of this training in the active avoidance context prior to active avoidance training.
\end{abstract}

When rats acquire more than one response in a single context, there is a tendency for these responses to interact with each other when the rats are returned to that training context for a retention test. One example of such response interactions occurs in what has been termed the " "memory interference paradigm." In this paradigm, rats are trained to perform conflicting responses in the same apparatus. Subsequently, when the animals are tested for retention of the most recently learned response, they perform more poorly than animals trained on that response alone (see Spear, 1971, 1978). In effect, training on the first response interferes with retention of the second response acquired.

In many ways, this memory interference effect is similar to the proactive interference phenomenon found in human verbal retention studies. In both situations, interference produced by prior learning increases as the retention interval following latest learning is increased (e.g., Gordon, Frankl \& Hambert, 1979; Keppel, 1968). Also, interference in both instances tends to decrease as the interval between prior and latest learning is increased (e.g., Gordon \& Spear, 1973; Underwood \& Freund, 1968). Finally, interference in both of these paradigms depends a great deal on the similarity of the stimuli embedded in the two learning tasks (see Spear, 1978).

Of particular importance in the memory interference paradigm appear to be the contextual stimuli present when an animal acquires the conflicing responses. In a series of experiments, Spear and his colleagues (Spear et al., 1980) demonstrated that the interference due to prior learning occurs to the degree that the prior learning context matches the context of more recent learning and testing. Having animals learn Task 1 in one context and Task 2 in another context resulted in greatly diminished

\footnotetext{
This research was supported by grants from the National Science Foundation and from the New Mexico Research Allocations Committee to the first author. Portions of these data were presented at the Animal Cognition and Behavior Symposium, University of Oklahoma, Norman, OK, 1982. Requests for reprints should be sent to William C. Gordon, Department of Psychology, University of New Mexico, Albuquerque, NM 87131.
}

interference when the test context was the same as that for Task 2 learning. This was the case when both external contextual stimuli and internal contextual stimuli (drug states) were manipulated.

To interpret such findings, Spear (1976) hypothesized that an animal's memory for a given response includes representations of all those stimuli noticed by the animal at the time of acquisition. Furthermore, retrieval of a particular memory is a direct function of the overlap between retention test stimuli and stimuli represented in a given memory. Thus, when two conflicting memories are acquired in the same context, these memories share a number of stimulus representations. If a retention test then occurs in the same context used for acquisition, the probability will be high that both memories will be retrieved and that these memories will compete for expression on the retention test. If, however, an animal acquires conflicting responses in different contexts, the memories of these two responses should contain very different stimulus representations, resulting in a low likelihood that both memories will be retrieved simultaneously.

It should be noted that the critical feature of this interpretation is that interference should occur whenever two memories contain similar stimulus representations. For this to occur, it has generally been assumed that an animal must acquire both memories in the same stimulus situation. However, recent evidence from our own laboratory suggests that this may not be the case. These studies (see Gordon, 1981, 1983) indicate that if animals are given a cue or reminder of a training experience in a novel context, the animals subsequently perform as though they had learned in that novel context. In other words, when a training memory is cued in the presence of novel stimuli, an animal later performs as though these novel stimuli had become represented in the memory of training.

If this is the case, then according to Spear's (1976) interpretation of interference effects, interference could occur even when conflicting responses are not actually acquired in the same context. All that would be necessary is that the memory of one response be cued in the same context in which a conflicting response is acquired. This 
procedure should result in similar stimulus representations in the two memories, and subsequent test interference should occur.

To test this prediction, the present experiment involved training rats on a passive avoidance response and then an active avoidance response in the same apparatus. This paradigm is known to produce substantial interference when both responses are trained in the same room (Gordon, 1977; Gordon \& Spear, 1973), but not when the responses are acquired in different rooms (Spear et al., 1980). The critical condition will involve training the two responses in different rooms but giving the animals a cue for passive avoidance training in the active avoidance training context. Should this procedure result in interference on a subsequent retention test, this would indicate that interference does not depend on acquisition of conflicting responses in the same context. It would support our hypothesis that when a memory is cued in a novel context, the novel context becomes represented in the cued memory.

\section{METHOD}

\section{Subjects}

The subjects were 30 male and 56 female Sprague-Dawley-derived albino rats ranging in age from 60 to 100 days.

\begin{abstract}
Apparatus
The apparatus consisted of two identically constructed avoidance apparatuses. Each apparatus consisted of one white translucent chamber and one black chamber. These Plexiglas chambers, each $27 \times 13 \times$ $13 \mathrm{~cm}$, were separated by a door that could be lowered (opened) to leave a 3-cm hurdle between the chambers. A 2- $\mathrm{Hz}$ flashing white light $(7.5 \mathrm{~W})$ located directly behind the white chamber could be activated by lowering the door and could be deactivated by breaking a photobeam located $13 \mathrm{~cm}$ into the black chamber. A .01-sec running time meter also could be activated by lowering the door and stopped by breaking the photobeam. Each apparatus contained a grid floor composed of .6-cm-diam steel rods set $1.7 \mathrm{~cm}$ apart. A scrambled footshock provided by a GraysonStadler shock generator (Model E1064GS) could be delivered through the grid floor of either chamber.

In addition to the avoidance apparatus, a clear Plexiglas footshock chamber $(36 \times 36 \times 69 \mathrm{~cm})$ was used. The floor was identical to that in the avoidance apparatuses, and footshocks could be delivered by the same shock source described above. The avoidance apparatuses were located in separate rooms (Rooms A and B). These rooms differed in terms of size, lighting, odor, and ambient noise level (see Table 1). A Sonalert tone generator (Mallory \& Co., Model 33391970) could be activated manually to deliver a $75-\mathrm{dB}, 2000-\mathrm{Hz}$ tone in either Room A or Room B.
\end{abstract}

\section{Design and Procedure}

On Days 1 and 2, all animals were removed from the vivarium and carried into an adjacent room where they were handled for $1 \mathrm{~min}$. On Day 3, all animals received some type of initial treatment (passive

Table 1

Physical Characteristics of Treatment Rooms

\begin{tabular}{lccc}
\hline & \multicolumn{3}{c}{ Room } \\
\cline { 2 - 4 } & $\mathrm{A}$ & $\mathrm{B}$ & $\mathrm{C}$ \\
\hline Dimensions (in feet) & $16.0 \times 7.5$ & $16.0 \times 11.0$ & $13.5 \times 7.5$ \\
Lighting (in ft-lumens) & Dark & Bright & Dim \\
Odor (Room deodorizer) & Lemon & Rose & None \\
Noise Level (in decibels) & Fan (63-65) & None (45-50) & None (45-50) \\
Gloves & Rough & Smooth & Textured \\
Holding cage & Wire mesh & Wooden & Plastic cage \\
\hline
\end{tabular}

avoidance training or noncontingent footshock treatment) followed $10 \mathrm{~min}$ later by active avoidance training. All animals were then tested for retention $1 \mathrm{~h}$ after active avoidance training. The animals spent both the intertask and the retention interval in the vivarium.

Passive avoidence training consisted of placing a rat in the white chamber of the avoidance apparatus such that the rat faced the door. After $3 \mathrm{sec}$, the door was opened, which initiated the flashing light. If the rat crossed into the black chamber within $60 \mathrm{sec}$, the door was closed and the rat immediately received a $3-\mathrm{sec} 1.6-\mathrm{mA}$ footshock. If the rat remained in the white chamber for $60 \mathrm{sec}$, the trial ended and a successful avoidance was recorded. Three seconds after either receiving a footshock or performing a successful avoidance, the rat was removed to a holding cage for a 30-sec intertrial interval (ITI). The criterion for passive avoidance training was two consecutive 60 -sec avoidances within 12 trials. Once an animal had met the training criterion, an additional 5 trials were conducted. Rats that failed to meet the training criterion were discarded.

Active avoidance training consisted of placing the rat in the white chamber of the avoidance apparatus such that the rat faced the door. After $3 \mathrm{sec}$, the door was lowered, which activated the flashing light. If a rat failed to cross into the black chamber and break the photobeam within $5 \mathrm{sec}$ after the door had been lowered, a 1.6-mA footshock was delivered and remained on until an escape response had occurred. Following an escape response, the chamber door was closed, and after $3 \mathrm{sec}$, the animal was removed and placed in a holding cage for a 30 -sec ITI. If a rat did cross into the black chamber within $5 \mathrm{sec}$ after the door had been opened, the door was closed, and after $3 \mathrm{sec}$, the rat was removed for the ITI. No shocks occurred on successful avoidance trials. The criterion for active avoidance acquisition was five consecutive avoidance responses within 20 trials. Rats that failed to meet this criterion or failed to receive a footshock within the first 4 training trials were discarded.

Retention testing consisted of five trials identical to the training trials except that no shocks were delivered. On each trial, the rat's latency to cross into the black chamber and break the photobeam was recorded. If a rat remained in the white chamber for $60 \mathrm{sec}$, the trial ended and a latency of $60 \mathrm{sec}$ was recorded.

Animals were assigned randomly to one of six treatment conditions $(\mathrm{n}=16)$, each containing 5 males and 11 females. The first group (Group BBB) received passive and active avoidance training as well as retention testing in Room B. A second group (Group NC) was identical to Group BBB, except that it received inescapable, noncontingent footshocks in place of passive avoidance training. Each rat's shocks were administered in the Plexiglas chamber and were matched in terms of sequence, duration, number, and intensity to that of a randomly chosen rat in Group BBB. The third group (Group ABB) differed in that passive avoidance training occurred in Room $A$ and was followed by active avoidance training and testing in Room B. On the basis of previous studies, we expected to find relatively poor retention of active avoidance for Group BBB (i.e., interference) and significantly better retention for Groups NC and ABB.

The rats in the remaining three conditions were treated identically to those in Group ABB, with the following exceptions. The rats in Group T-T were exposed to a continuous tone throughout passive avoidance training in Room $A$. Then these animals were reexposed to

remind them of passive avoidance learning in the new context. Specifically, the cuing treatment involved bringing the rats into Room B approximately $4 \mathrm{~min}$ prior to the start of active avoidance training and placing them in a holding cage. The tone then was presented for $15 \mathrm{sec}$. After tone offset, the rats remained in the holding cage in Room B for $3.5 \mathrm{~min}$. Immediately thereafte-, active avoidance training was begun. The tone was absent during both active avoidance acquisition and retention testing. Rats in Group T-NT received the same treatment as those in Group T-T, except that they did not receive the tone in Room B. The final group, Group NT-T, was the same as Group T-T, except that they did not receive the tone during passive avoidance learning in room $\mathrm{A}$.

\section{RESULTS}

Fifteen animals were discarded during the experiment, either for failure to reach the passive or active avoidance 
criterion or for apparatus failure. Since these animals were approximately equally distributed across groups, each discarded rat was replaced with a rat that had the same characteristics. The mean number of trials to reach the passive avoidance criterion ranged from 3.1 (Group BBB) to 4.0 (Groups T-T and NT-T). An analysis of variance performed on these data indicated no significant group differences in trials to reach the training criterion $[F(4,75)$ $=1.88 \mathrm{]}$, suggesting that, prior to the different treatments, the groups did not differ in degree of training (for this and all subsequent analyses, a rejection criterion of .05 was used).

The mean number of trials for each group to attain the active avoidance criterion ranged from 7.1 (Group BBB) to 10.1 (Group T-T). The analysis of variance performed on these data again indicated no significant differences between groups in the rate of active avoidance acquisition $[F(5,90)=1.40]$. Importantly, these data suggest that the different prior training and cuing exposures did not differentially affect the active avoidance acquisition rates of the treatment groups.

Two measures of retention test performance were analyzed in this experiment. The first measure was a rat's latency to move into the black chamber on Test Trial 1. Prior to analysis, these latencies were converted to log latency scores because of wide variation in individual group variance. The mean log latencies for each treatment condition are presented in Figure 1.

In Figure 1, short log latencies represent a tendency to perform in accord with the more recently trained active avoidance contingencies, whereas longer log latencies reflect a decrease in this tendency. An analysis of variance performed on these data revealed a significant effect of treatment condition $[F(5,90)=8.88]$. Individual group comparisons were made with critical difference tests (Lindquist, 1956). These tests revealed that Groups BBB and $\mathrm{T}-\mathrm{T}$ exhibited significantly longer latencies than did any of the remaining groups. Also, the animals in Group NC had significantly shorter latencies than the

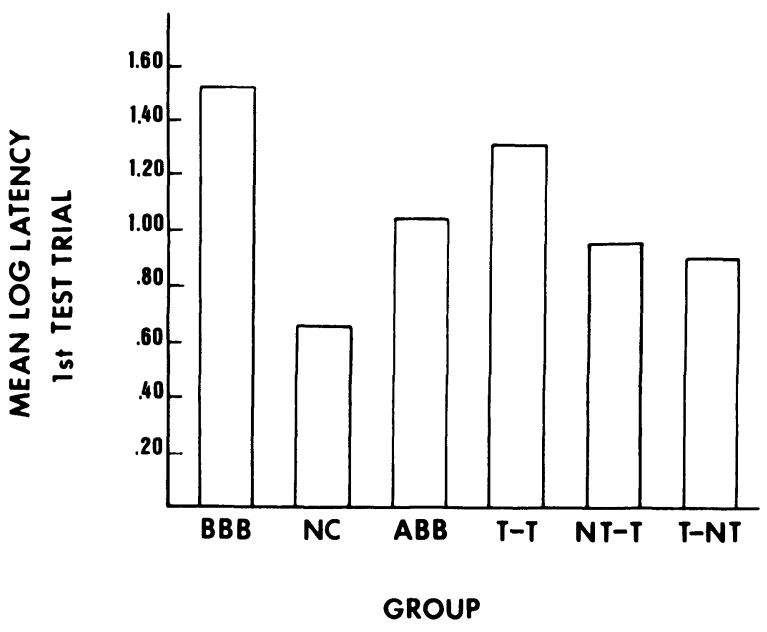

Figure 1. Mean log latencies (in seconds) on Test Trial 1 as a function of treatment condition. animals in all groups except Group T-NT. No other significant differences were obtained.

The second retention measure used was each animal's average latency over the five test trials. As with the Trial 1 latencies, these average latency scores were converted to logs prior to analysis. An analysis of variance performed on these data again revealed a significant treatment effect $[F(5,90)=6.88]$. Critical difference tests showed that this effect resulted from exactly the same group differences evident in the Trial 1 latency data. Groups T-T and BBB exhibited significantly longer latencies that all other groups, and Group NC had significantly shorter latencies than all groups except Group T-NT.

Taken together, these results show that prior passive avoidance training can interfere with retention of active avoidance even when the two responses are learned in different contexts (see Groups NC and ABB). However, this interference can be enhanced significantly if both responses are acquired in the same context (see Groups $\mathrm{ABB}$ and $\mathrm{BBB})$. Importantly, it appears that such interference also can be enhanced if animals are reminded of the passive avoidance response in the same context in which active avoidance is learned (see Groups ABB and T-T). This increased interference in Group T-T apparently is not due simply to the fact that these animals received a tone during passive avoidance learning (see Group T-NT). Furthermore, this increase in response latency does not seem to result simply from a tone presentation in the active avoidance context prior to training there (see Group NT-T). Apparently, the tone presentation prior to active avoidance training enhances interference only when that tone was present during passive avoidance learning and, thus, could reasonably be expected to remind the animals of the passive avoidance response.

\section{DISCUSSION}

These findings replicate studies cited earlier (e.g., Spear et al., 1980) that showed that interference is more pronounced when animals acquire conflicting responses in the same context. Thus, the present findings are consistent with Spear's (1976) hypothesis that interference depends on the similarity of the representations in two conflicting memories. Memories acquired in the same context should have certain contextual representations or attributes in common, whereas memories acquired in different contexts normally would be expected to share fewer representations.

The most significant finding in the present experiment, however, is that substantial interference can occur even when animals acquire conflicting memories in very different contexts. Such interference results, in this instance, as long as animals are reminded of one training episode and undergo training on a conflicting response in the same context. This finding clearly is at odds with Spear's (1976) interpretation of interference effects, if one asumes that contextual stimuli can become represented in a training memory only by an animal noticing those stimuli at the time of the training. However, this result follows directly from Spear's hypothesis if we make a different assumption concerning when stimuli can become represented in a training memory. Spear's hypothesis predicts the present result if we assume that not only training stimuli, but also stimuli present at the time a training memory is cued or retrieved can become represented in that training memory.

Previous work in our laboratory lends credence to such an assumption. First, we have shown that performance deficits normally associated with training and testing rats in different contexts can be alleviated by reminding animals of the training response in the test context prior to 
testing (Gordon, McCracken, Dess-Beech, \& Mowrer, 1981). In other words, animals cued in the test context perform as though they had been trained in that context. Similarly, we found that pretest cuing procedures normally facilitate test performance to a much greater extent if these cues are presented in the training-testing context than if cuing occurs in an irrelevant context. However, we demonstrated that pretest cuing in an irrelevant context could be made effective by giving animals prior cuing treatments in the irrelevant context at the time of training (Wittrup \& Gordon, 1982). In effect, animals given the prior cuing treatments performed as though pretest cuing had been delivered in the training context, not an irrelevant context. Finally, we replicated the finding that runway training in multiple contexts results in prolonged extinction of running relative to runway training in a single context. However, we also found that animals trained in one context and cued in a second context exhibited prolonged extinction (Gordon, 1983). Again, arimals cued in a novel context performed as though they had been trained in that context.

Together, these findings suggest that the contextual control of retention performence normally exerted by a training context also is exerted by contextual stimuli present when an animal is cued or reminded of a training experience. Our interpretation of these findings has been that stimuli noticed by an animal when a memory is cued become represented in that cued memory and later can control performance related to that memory (see Gordon, 1981, 1983). Thus, we assume that in the present experiment, the Group T-T animals experienced interference at the time of testing because both the passive and active avoidance memories contained representations of Context $B$. The active avoidance memory contained these representations because that memory was acquired in Context $B$. The passive avoidance memory contained these representations because that memory was cued in Context $\mathrm{B}$ prior to active avoidance training.

Aside from the present finding, at least one result of earlier interference studies may be amenable to this interpretation. Several studies have shown that memory interference in rats occurs only when the two conflicting responses are learned close together in time. Interference tends to be minimal with long intertask intervals even when both responses are acquired in the same "experimenter-defined" context. There are reports, however, that interference can occur even with lengthy intertask intervals as long as animals are reminded of the first task shortly before learning the second, conflicting task (e.g., Gordon, 1977; Gordon, Frankl, \& Hamberg, 1979; Gordon \& Spear, 1973).

The interpretation placed on this finding was that interference could occur only to the extent that the activation of two memories (one through acquisition and the other through cuing) overlapped. Although such an interpretation remains plausible, the present findings suggest one reason why concurrent activation of two memories might be important in producing interference. We can reasonably assume that at least part of an animal's internal and external context is determined by temporal factors. For example, an animal's hormonal milieu at one time of day may be quite different from that at another time of day. Similarly, passage of time should be related to maturation or aging, which should alter an animal's internal context and should, at the least, modify an animal's perception of its external context. Thus, we might expect that when memories are acquired far apart in time, the contextual representations in these memories should be less similar than if such memories are acquired contemporaneously. Reminding an animal of one response just prior to its acquisition of a conflicting response may increase the similarity of contextual representations in the two memories. This would help to explain why such a procedure might increase memory interference in the rat.

\section{REFERENCES}

GoRdon, W. C. (1977). Similarities between short-term and reactivated memories in producing interference in the rat. American Journal of Psychology, 90, 231-242.

GoRDon, W. C. (1981). Mechanisms for cue-induced retention enhancement. In N. E. Spear \& R. R. Miller (Eds.), Information processing in animals: Memory mechanisms. Hillsdale, NJ: Erlbaum.

GoRDON, W. C. (1983). The malleability of memory in animals. In R. L. Mellgran (Ed.), Animal cognition and behavior. New York: NorthHolland.

Gordon, W. C., Frankl, S. E., \& Hamberg, J. M. (1979). Reactivation-induced proactive interference in rats. American Journal of Psychology, 92, 693-702.

Gordon, W. C., McCracken, K. M., Dess-Beech, W., \& Mowrer, R. R. Mechanisms for the cueing phenomenon: The addition of the cueing context to the training memory. Learning and Motivation, 12, 196-211.

GoRdon, W. C., \& SPEAR, N. E. (1973). The effect of reactivation of a previously acquired memory on the interaction between memories in the rat. Journal of Experimental Psychology, 99, 349-355.

KEPPEL, G. (1968). Retroactive and proactive inhibition. In T. R. Dixon \& D. L. Horton (Eds.), Verbal behavior and general behavior theory. Englewood Cliffs, NJ: Prentice-Hall.

LINDQUIST, E. F. (1956). Design and analysis of experiments in psychology and education. Boston: Houghton-Mifflin.

SPEAR, N. E. (1971). Forgetting as retrieval failure. In W. K. Honig \& P. H. R. James (Eds.), Animal memory. New York: Academic Press.

SPEAR, N. E. (1976). Retrieval of memories: A psychobiological approach. In W. K. Estes (Ed.), Handbook of learning and cognitive processes: Vol. 4. Attention and memory. Hillsdale, NJ: Erlbaum.

SPEAR, N. E. (1978). The processing of memories: Forgetting and retention. Hillsdale, NJ: Erlbaum.

Spear, N. E., Smith, G. J., Bryan, R. G., Gordon, W. C., TimMONS, R., \& ChiszaR, D. A. (1980). Contextual influences on the interaction between conflicting memories in the rat. Animal Learning \& Behavior, 8, 273-281.

UNDERWOOD, B. J., \& FREUND, J. S. (1968). Effect of temporal separation of two tasks on proactive inhibition. Journal of Experimental Psychology, 78, 50-54.

(Manuscript received for publication February 21, 1985.) 